\title{
Knowledge of tuberculosis-treatment prescription of health workers: a
}

\section{systematic review}

\author{
Marieke J. van der Werf*\#, Miranda W. Langendam", \\ Emma Huitric $^{+}$and Davide Manissero ${ }^{+}$
}

ABSTRACT: Treating tuberculosis (TB) patients with inappropriate treatment regimens can lead to treatment failure and, thus, patients who have not been cured and/or to the development of (multi)-drug resistance. A systematic review was performed to assess the knowledge of appropriate TB drug regimens among all categories of healthcare workers (HCWs).

In January 2011, MEDLINE, EMBASE and other databases were searched for relevant articles. Observational studies published as of the year 2000 that assessed HCW knowledge of TB treatment were selected. A treatment regimen, drug dosage or treatment duration was considered inappropriate if it was not recommended by national guidelines or by the World Health Organization (WHO).

Of 1,896 studies, 31 were included from 14 different countries. No study was performed in Europe. In all studies, HCWs with inappropriate knowledge of treatment regimens (8-100\%) or treatment duration (5-99\%) were observed. The few studies providing detailed data showed that HCWs mainly reported giving treatment regimens with too many drugs and for too long. Knowledge of appropriate doses was also insufficient in most studies.

The available studies show that there is a lack of knowledge of national or international TB treatment guidelines and recommendations. Generalisation of the findings to other settings and countries should be done with caution.

KEYWORDS: Healthcare workers, inappropriate, regimen, treatment, tuberculosis

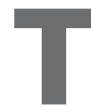
reating tuberculosis $(\mathrm{TB})$ patients with inappropriate $\mathrm{TB}$ treatment regimens, i.e. regimens that are not in accordance with the World Health Organization (WHO) treatment guidelines [1-4], can result in the development of multidrug-resistant (MDR)-TB [5]. A systematic review published as part of this series in the European Respiratory Journal assessed the percentage of $\mathrm{TB}$ patients that received an inappropriate treatment regimen [6]. 37 studies were included. The studies were from 22 countries, and one study was from multiple countries. Almost all continents were represented. In $67 \%$ of the studies, inappropriate treatment regimens were prescribed. The percentage of patients receiving inappropriate regimens ranged between $0.4 \%$ and $100 \%$. In 19 studies, detailed information on the treatment regimen was missing.
The prescription of adequate TB treatment (regimen, dosage and duration) requires knowledge of existing treatment recommendations. Since 1993, the WHO has published and updated international TB treatment guidelines [1-4], aiming to provide national TB programmes (NTPs) and the medical profession with evidence-based, practical guidance on effective TB case management. Many countries have considered and included these recommendations in their own national TB guidelines. Studies, often described as knowledge, attitude and practice studies, assessing whether these recommendations are known to individual healthcare workers (HCWs) have been performed. These studies commonly measure either the extent of knowledge about TB treatment among HCWs, or the HCWs' intended behaviour ("What treatment would you prescribe for a TB patient?").

Previous articles in this series: No. 1: Langendam MW, van der Werf MJ, Huitric E, et al. Prevalence of inappropriate tuberculosis treatment regimens: a systematic review. Eur Respir J 2012; 39: 1012-1020.

AFFILIATIONS

*KNCV Tuberculosis Foundation, The Hague,

${ }^{\#}$ Center for Infection and Immunity Amsterdam (CINIMA),

"Dutch Cochrane Centre, Academic Medical Center, University of Amsterdam, Amsterdam, The Netherlands.

+European Centre for Disease Prevention and Control (ECDC), Stockholm, Sweden.

CORRESPONDENCE

M.J. van der Werf

European Centre for Disease

Prevention and Control (ECDC)

SE-171 83 Stockholm

Sweden

E-mail: marieke.vanderwerf@

ecdc.europa.eu

Received:

July 222011

Accepted after revision:

Sept 222011

First published online:

Dec 192011

This article was modified in April 2016 to correct errors in the licence information. 
To add to the evidence obtained in the systematic review on TB treatment regimens prescribed to $\mathrm{TB}$ patients [6] and to investigate a possible cause for inappropriate treatment, we conducted a systematic review of the literature to specifically assess the knowledge of appropriate $\mathrm{TB}$ drug regimens among HCWs (i.e. "do HCWs know what type of drugs, dosage and duration of treatment are recommended by national guidelines or the WHO treatment guidelines?"). For the purpose of this study, HCWs are defined as individuals working in public and/or private healthcare facilities, and those undergoing medical training (medical students and interns).

\section{METHODS}

We followed the Cochrane Handbook for Systematic Reviews [7] and the Preferred Reporting Items for Systematic Reviews and MetaAnalyses (PRISMA) statement [8].

\section{Search strategy}

To identify relevant studies we conducted a literature search in the bibliographic databases MEDLINE and EMBASE on January 6,2011 . We also searched for guidelines in the National Guideline Clearinghouse and other guideline databases. Abstracts of conference proceedings were sought in BIOSIS. Reviews and guidelines were searched for in the TRIP data base (January/ February 2011).

Keywords used in the search were determined in collaboration with the clinical librarian of the Dutch Cochrane Centre and included "Tuberculosis" OR "TB" OR "Mycobacterium" AND for TB treatment "Prescriptions" OR "Treatment regimen" OR "Combination treatment" OR "Treatment strategy/-ies" OR "Drug supply" OR "Standard treatment/standard regimen" OR "Inappropriate use, appropriate use, rational use, irrational use, misuse". The search was limited to the publication years 2000-2010 as we were interested in "current" knowledge of treatment guidelines. We did not limit the search to a geographical area or countries. Also, we did not use any language restriction. If an English language abstract was available that provided the necessary information, the article was included. We excluded case reports. The search strategy was supplemented by hand searching reference lists of included articles and identifying relevant review articles.

\section{Selection of studies}

We included observational studies among HCWs assessing knowledge of TB treatment (regimen, dosage, duration) or intended prescription practices ("What treatment would you prescribe?"). For both knowledge and intended prescription practices, we will use the term "knowledge" in this paper. We excluded studies that did not report knowledge of the treatment regimen, dosage or treatment duration in sufficient detail to make a judgment on the appropriateness and in which the authors did not make a statement about appropriateness. Studies identified by the search strategy were reviewed for eligibility based on title and abstract by one investigator (M.J. van der Werf). Full manuscripts of the references selected based on title/abstract were assessed by one investigator (M.J. van der Werf). For both steps, a $10 \%$ random sample was assessed by a second investigator (M.W. Langendam) and compared with the assessment of the first reviewer. Inconsistencies in assessment were discussed and disagreements resolved by consensus. A complete double selection was planned if the $10 \%$ random sample revealed relevant inconsistencies. There were no relevant inconsistencies.

\section{Data extraction}

One reviewer (M.J. van der Werf) extracted all relevant data items from the included studies using a data extraction form. This included the following items: year of publication; country where study was performed; study setting; aim of the study; period of data collection; type of HCW; selection method (of respondents); method of data collection; number of respondents selected/ invited; number of respondents participating; any information on nonrespondents; characteristics of included HCWs (sex, age, education, etc.); number of TB cases seen by each HCW ("experience"); intended or observed TB treatment; type of TB patient for which treatment is reported; TB treatment regimen; TB treatment dose; TB treatment duration; and prevalence of inappropriate regimen according to authors. A second reviewer (M.W. Langendam) checked the extracted results. Inconsistencies were discussed to obtain consensus.

\section{Data analysis and synthesis of results}

The results were summarised qualitatively. For studies describing treatment regimens reported by HCWs, but without indicating whether they were appropriate according to national or WHO guidelines, the reported regimens were assessed and assigned to the appropriate or inappropriate category by the authors using the WHO treatment guidelines [1-3]. Table 1 lists the applicable WHO treatment guideline for different periods. One reviewer assessed the regimens (M.J. van der Werf) and the other reviewer (M.W. Langendam) cross-checked the assessment. The adequacy of knowledge of HCWs on regimen, dose and duration of TB treatment is summarised. We present results for $\mathrm{HCWs}$ in private settings and in public settings.

\section{RESULTS \\ Study selection}

The search in MEDLINE and EMBASE resulted in 1,896 unique references. A total of 21 papers were considered relevant (fig. 1). The National Guideline Clearinghouse, National Institute for Health and Clinical Excellence (NICE), Scottish Intercollegiate Guidelines Network (SIGN) and TRIP databases did not provide aggregated evidence of knowledge of TB treatment by HCWs. In BIOSIS, 583 references were identified using the keywords "tuberculosis AND treatment" on May 20, 2011. Assessment of these references did not provide new references.

Checking the reference lists of the included papers revealed 10 relevant studies. Thus, in total, 31 articles were included in the review. For two studies, only abstracts were available [20, 21].

\begin{tabular}{lll}
\hline TABLE 1 & $\begin{array}{l}\text { Applicability of the different World Health } \\
\text { Organization (WHO) treatment of tuberculosis } \\
\text { guidelines }\end{array}$ \\
$\begin{array}{l}\text { Period of data } \\
\text { collection }\end{array}$ & WHO guidelines & \\
\hline $\mathbf{1 9 9 5 - 1 9 9 9}$ & First edition: 1993 & {$[1]$} \\
$\mathbf{1 9 9 9 - 2 0 0 4}$ & Second edition: 1997 & {$[2]$} \\
$\mathbf{2 0 0 5 - 2 0 1 0}$ & Third edition: 2003 & {$[3]$} \\
\hline
\end{tabular}




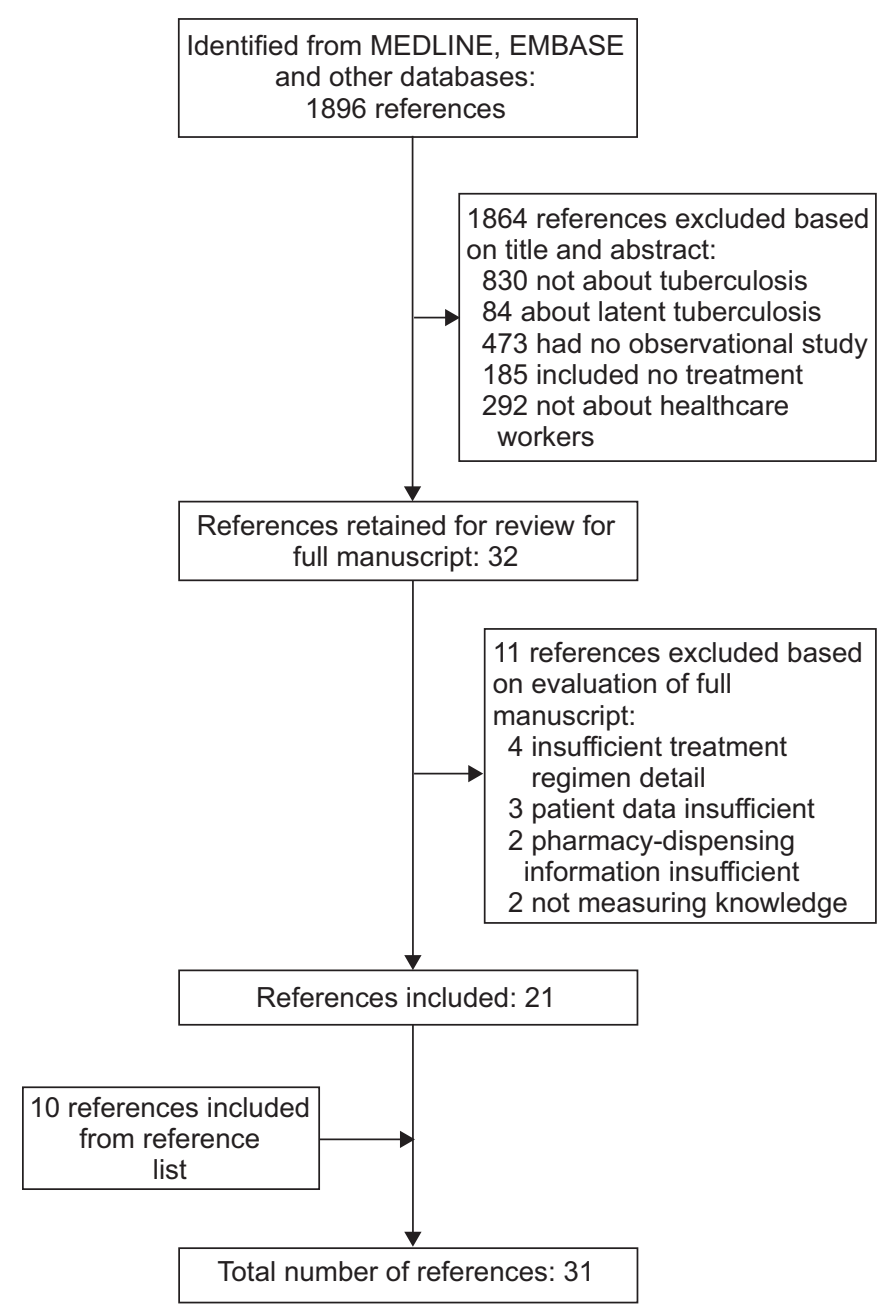

FIGURE 1. Summary of literature search and study selection. References were excluded based on evaluation of the full manuscript according to: treatment regimen given in insufficient detail [9-12]; level of patient data insufficient [13-15]; insufficient pharmacy dispensing information [16, 17]; and not measuring knowledge $[18,19]$.

\section{Description of included studies}

The objective of 29 of the 31 included studies was either to assess knowledge of TB treatment and/or intended practices on TB treatment, or to assess HCW compliance with the treatment guidelines. One study's objective was "to identify the factors preventing a better understanding of TB as a social and medical problem" [22] and one study, of which only an abstract was available, did not specify the objective [21].

The median sample size of the included studies was $114 \mathrm{HCW}$ (range 22-1,355). The studies were performed in 14 different countries (table 2), of which 14 (45.2\%) were in either India or Pakistan. Almost all continents were represented: South Asia (15 studies), East and South East Asia (five studies), South West Asia (four studies), Africa (five studies), the Americas (two studies). There were no studies from Europe.

A self-administered questionnaire was used in 12 (38.7\%) studies $[20,23,24,27,29-31,34,36,41,44,50]$ and, in 13 (41.9\%) studies, participants were interviewed using a questionnaire $[19,22,28$,
37-40, 43, 45, 46-49]. Four (12.9\%) used a questionnaire but did not specify whether it was performed by interview or was a selfadministered questionnaire [25, 32, 33, 42]. Two studies did not report how the data were collected $[21,26]$.

$11(35.5 \%)$ studies selected $\mathrm{HCWs}$ using random selection methods $[20,22,28,30,32,33,37,41,44,48,49]$ and $10(32.3 \%)$ included all eligible individuals [23, 25, 27, 29, 31, 34, 39, 46, 47, 50]. Six (19.4\%) studies used convenience- or purposefulsampling, or included HCWs who wanted to participate [24, $35,36,38,40,45]$ and four $(12.9 \%)$ studies did not specify the selection method [21, 26, 42, 43].

$16(51.6 \%)$ studies were performed among HCWs practising in a private setting [24, 25, 28, 30, 31, 32, 34, 36, 37, 39-41, 44-46, 49], three $(9.7 \%)$ among both HCWs practising in a private setting and in a public setting $[29,47,48]$, three $(9.7 \%)$ among medical students or interns $[20,21,27]$, and nine $(29.0 \%)$ studies did not specify whether the HCWs were practising in a private or public setting $[22,23,26,33,35,38,42,43,50]$ (table 3 ).

\section{Prevalence of inappropriate knowledge of TB treatment}

The percentage of HCWs with inappropriate knowledge of TB regimens in the studies among private providers ranged between $20 \%$ and $100 \%$ (median $74 \%$; table 3); in one study the level was reported as $>41 \%$ [39]. The level of inappropriate knowledge of treatment regimens ranged between $8 \%$ and $93 \%$ (median $73 \%$ ) among HCWs practising in settings other than uniquely private. Three studies did not provide the data to assess the percentage $[22,29,42]$, in one study it was $<25 \%$ [26] and in another study $>55 \%$ [27].

15 studies provided information on HCWs experience in treating TB patients $[25,30,31-34,36,38-40,42,46-48,50]$. In the 10 studies where $\geqslant 80 \%$ of the HCWs managed TB cases, or where the average number of TB cases managed per HCW was at least five per month, $8 \%$ to $100 \%$ had inappropriate knowledge of the recommended treatment regimen (median 61.5) [25, 30-34, 38, 39, $48,50]$.

Six studies provided data that allowed assessing whether HCWs' knowledge on the number of different drugs required in a TB treatment regimen was adequate, or whether they would prescribe too many or too few drugs. Three studies specifically reported on HCWs practising in a private setting. AuER et al. [39] reported that nine $(20 \%)$ out of 45 private practitioners would prescribe fewer than four drugs in the intensive phase for faradvanced TB; this is $22 \%$ of all inappropriate answers reported in the study. KHAN et al. [34] reported that 10 out of 120 private physicians would prescribe fewer than four drugs in the intensive phase for pulmonary $\mathrm{TB}$, i.e. $63 \%$ of all reported inappropriate treatment in the intensive phase. In another study, $2 \%$ of private practitioners would prescribe three drugs for sputum-positive pulmonary TB [25], whereas $18 \%$ would prescribe an inappropriate regimen of four or five drugs.

Three studies among HCWs for which the setting was not specified provided information about prescription of more or less than four drugs during the intensive phase. CIRIT et al. [43] reported that $98(60 \%)$ out of 162 physicians prescribed fewer than four drugs for newly diagnosed TB. Of 84 family physicians with an interpretable answer in the study by Rizvi et al. [33], 20 $(25 \%)$ would prescribe a one-, two- or three-drug regimen for 
TABLE 2 Characteristics of the included studies and prevalence of inappropriate regimens

\begin{tabular}{|c|c|c|c|}
\hline First author [ref.] & Country & $\begin{array}{l}\text { Study } \\
\text { setting }\end{array}$ & $\begin{array}{l}\text { Period of data } \\
\text { collection }\end{array}$ \\
\hline
\end{tabular}

Sample size $\mathbf{n}$

\section{South Asia}

AGARWAL [23]

ROY [24]

UDWADIA [25]

BHALLA [26]

RAJPAL [27]

GREAVES [28]

VANDAN [29]

DATTA [30]

HURTIG [31]

SHAH [32]

RIZVI [33]

KHAN [21]

KHAN [34]

SHEHZADI [35]

AHMED [36]

\section{East and South East Asia}

\section{BAl [20]}

MAHENDRADHATA [37]

YU [38]

AUER [39]

PORTERO [40]

\section{South West Asia}

SHIRZADI [41]

HASHIM [22]

DEVECI [42]

CIRIT [43]

\section{Africa}

SHIMELES [44]

AYAYA [45]

ChAKAYA [46]

SULEIMAN [47]

NSHUTI [48]

\section{Americas}

DATO [49]

LoBue [50]

India
India
India
India
India

Conference

Municipal area

Slum

Medical institute

Medical schools

India

India

India

Nepal

Pakistan

Pakistan

Pakistan

Pakistan

Pakistan

Pakistan

China

Indonesia

Philippines

Philippines

Philippines

Iran

Iraq

Turkey

Turkey

Ethiopia

Kenya

Kenya

Somalia

Uganda

Argentina

USA
City

City

Teaching hospitals

City

Regions

Rural district

Medical schools

$$
\text { City }
$$

Tertiary care hospital

Urban district

(Metro Manilla)

Country

Large cities

Public health

centres in the

country

City

City

City

Cosmopolitan town

$$
\text { Slum }
$$

Part of country

Urban district

County
2006

NR

NR

NR

2002

2006

2007

2008

1998

NR

NR

NR

2002

2003

2007

NR

2004

NR

1999-2000

2001

2001-2002

2001-2002

NR

2001

2003

NR

2001

2001

1999

2007

NR
National and international orthopaedic faculty and infectious disease experts

Qualified private medical practitioners

Private medical practitioners

Residents and faculty members from various departments

Interns that had gone through their training in various disciplines of medicine

Private practitioners

Medical physicians (public and private)

Private allopathic physicians

Licensed allopathic for profit private practitioners which were assumed to see TB patients

Formally qualified medical graduates who were practising medicine outside the government sector and who had managed at least one pulmonary TB patient during the

$$
\text { previous year }
$$

Family physicians that had no postgraduate qualification and were treating at least 7-10 TB patients per month

$$
\begin{gathered}
\text { Interns } \\
\text { Qualified private practitioners } \\
\text { General practitioners }
\end{gathered}
$$

Private practitioners with basic medical degree and doing private practice for $\geqslant 1 \mathrm{yr}$

Final year medical students

$$
\text { Private practitioners }
$$

Specialist physicians who dealt with pulmonary TB patients

$$
\text { Private for-profit practitioners who treat TB }
$$

$$
\text { Private physicians }
$$

Private sector physicians

$$
\text { HCWs }
$$

Practising physicians who provide first-line treatment Physicians

Private, for-profit medical doctors

Medical doctors practising privately

$$
\text { Private HCWs }
$$

Qualified medical practitioners (public and private sector)

Doctor or medical assistant from public and private clinics

Private doctors: general practitioners, infectious disease specialists and pulmonologists

Physicians who reported a TB suspect or case to the San Diego County Tuberculosis Control for the years 1995-1997
52

55

HCW: healthcare worker; NR: not reported; TB: tuberculosis. 


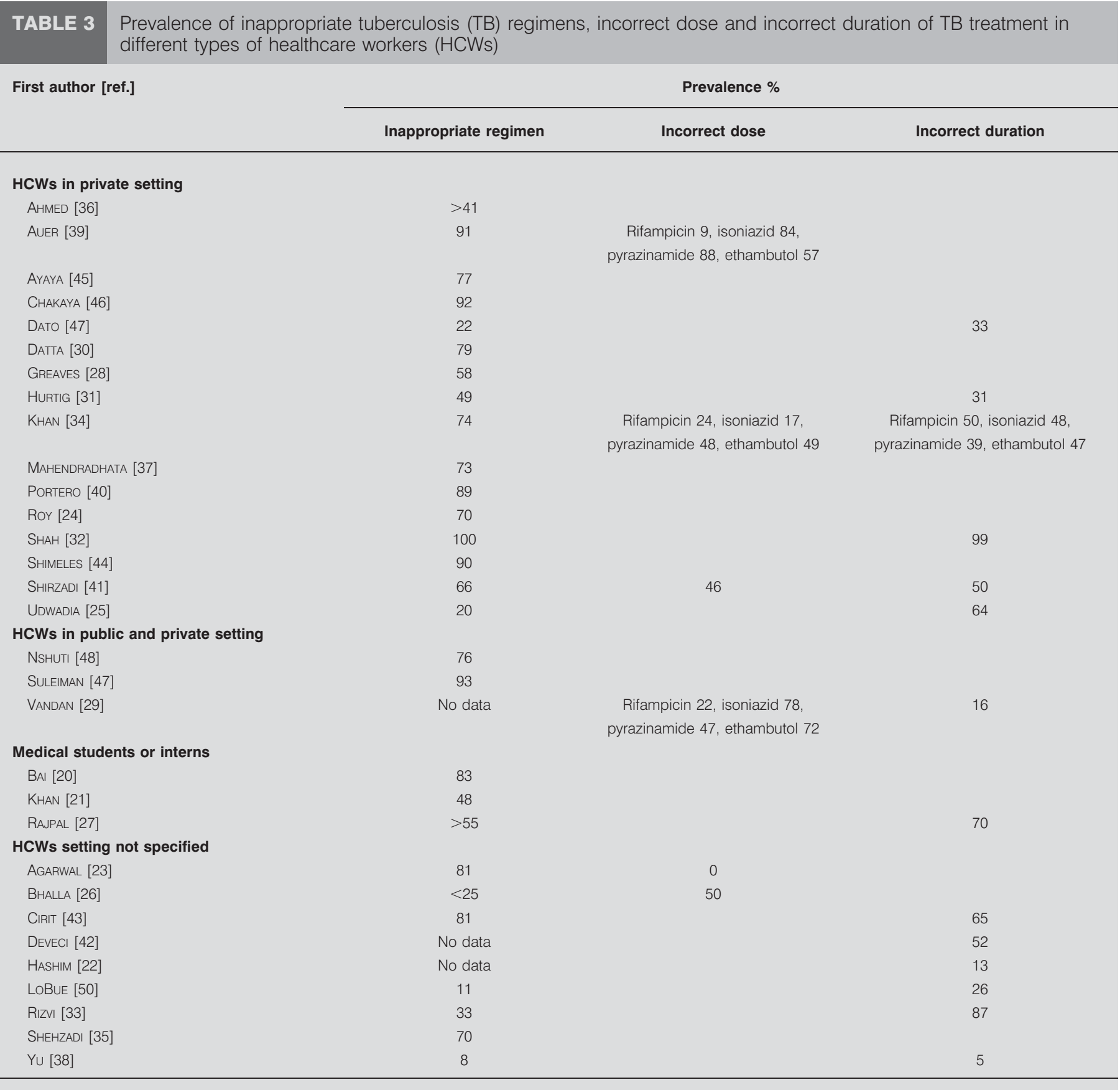

newly diagnosed pulmonary TB and six $(8 \%)$ an inappropriate regimen of more than four drugs. Yu et al. [38] reported that all HCWs reporting an inappropriate prescription (8\%) would prescribe a three-drug regimen for pulmonary TB [38].

Six studies reported on the knowledge of TB drug-dose in regimens (table 3) $[23,26,29,34,39,41]$. One study reported all mentioned doses as adequate [23]. Two studies reported that $46 \%$ [41] and 50\% [26] of the HCWs would prescribe an incorrect dose (either too low or too high). Three studies reported on knowledge of dose by individual drug (table 4) [29, 34, 39]. In two studies, high doses were more frequently mentioned [34, 39] than low doses for most drugs and, in one study, participants would more frequently prescribe low doses of isoniazid, pyrazinamide and ethambutol [29]. For rifampicin, the participants would more frequently prescribe high doses.

Knowledge of the duration of treatment regimens was reported in 13 studies $[22,25,27,29,31-33,38,41-43,49,50]$. Between $1 \%$ and $95 \%$ of the HCWs knew the correct duration of treatment. Overall, only a few HCWs would prescribe a regimen that was too short (<6 months): 3\% [31]; 8\% [25]; 11\% [27]; 52\% [43]; 4\% [22]; and none in the studies reported by RIZVI et al. [33] and YU et al. [38].

\section{DISCUSSION}

The studies included in this systematic review show that a large proportion of HCWs do not know or do not intend to 


\begin{tabular}{|c|c|c|c|c|c|c|}
\hline TABLE 4 & $\begin{array}{l}\text { Percenta } \\
\text { an inade } \\
\text { in three }\end{array}$ & $\begin{array}{l}\text { age of he } \\
\text { equate } \mathrm{d} \\
\text { studies }\end{array}$ & $\begin{array}{l}\text { althcar } \\
\text { ose for } \\
\text { rovidin }\end{array}$ & $\begin{array}{l}\text { workel } \\
\text { he four } \\
\text { inform }\end{array}$ & $\begin{array}{l}\text { that re } \\
\text { irst-line } \\
\text { ation }\end{array}$ & $\begin{array}{l}\text { orted } \\
\text { drugs }\end{array}$ \\
\hline \multirow[t]{2}{*}{ Drug } & \multicolumn{2}{|c|}{ AUER [39] } & \multicolumn{2}{|c|}{ КHAN [34] } & \multicolumn{2}{|c|}{ VANDAN [29] } \\
\hline & $\begin{array}{l}\text { Too } \\
\text { low }\end{array}$ & $\begin{array}{l}\text { Too } \\
\text { high }\end{array}$ & $\begin{array}{l}\text { Too } \\
\text { low }\end{array}$ & $\begin{array}{l}\text { Too } \\
\text { high }\end{array}$ & $\begin{array}{l}\text { Too } \\
\text { low }\end{array}$ & $\begin{array}{l}\text { Too } \\
\text { high }\end{array}$ \\
\hline Rifampicin & 1 (2) & $3(7)$ & $20(20)$ & $5(4)$ & $0(0)$ & $28(22)$ \\
\hline Isoniazid & $2(4)$ & $36(80)$ & $6(6)$ & $13(11)$ & $98(75)$ & 3 (2) \\
\hline Pyrazinamide & $2(5)^{\#}$ & $35(83){ }^{\#}$ & $15(15)$ & $40(33)$ & $43(33)$ & $18(14)$ \\
\hline Ethambutol & $10(33)^{\bullet}$ & $7(23)^{\bullet}$ & $10(10)$ & 47 (39) & $83(64)$ & $11(8)$ \\
\hline
\end{tabular}

prescribe regimens that follow the recommended national or international guidelines.

Treatment with too few drugs and for a too short duration has been shown to result in ineffective treatment outcomes of patients. Specifically, patients treated with regimens in which rifampicin is only given for the first 1 to 2 months, i.e. only used in the intensive treatment phase, have significantly worse treatment outcomes compared with regimens with rifampicin throughout therapy. Furthermore, these patients have an increased risk of acquiring rifampicin resistance [51]. It has also been shown that treatment with fewer than four drugs in the intensive phase results in higher percentages of relapse cases [52]. It is on this basis that, for new pulmonary TB patients, WHO guidelines recommend a regimen containing isoniazid, rifampicin, pyrazinamide and ethambutol in the 2-month intensive treatment phase, and isoniazid and rifampicin in the 4-month continuation treatment phase [4]. The studies observed in this review, in which HCWs reported prescribing too few drugs, are therefore of concern, both for the treatment outcome of patients and for the risk of resistance development. Three studies, without a specified setting (private or public), reported a higher frequency of treatment with fewer than four drugs compared with treatment with more than four drugs [33, 38, 43].

A known cause of treatment default is the burden of drug sideeffects to patients $[53,54]$. Three studies among HCWs practising in a private setting reported a higher frequency of treatment with too many drugs among this group of HCWs $[34,39,25]$. While it is essential to treat TB with the recommended number of drugs and for the correct duration, due to the side-effects caused by several drugs (especially in HIV-infected TB patients), the use of too many drugs should be avoided [55-57]. This is further supported by the knowledge that treatment with an increased number of drugs, such as the treatment of MDR-TB, is known to cause a higher frequency of side-effects [58] and is a known cause of default from treatment $[53,54]$. Based on this, prescribing more drugs than officially recommended should be discouraged so as to reduce development of side-effects and, thus, default from treatment.

For most drugs, the occurrence of side-effects is dose dependent [59] and, thus, prescribing a higher dose will give a higher chance of side-effects. In the three studies providing information on intended prescription of high doses $[29,34,39]$, there was no clear tendency for excessive doses to be more frequently prescribed than insufficient doses.

It should be noted that the included study populations in the identified studies might not be representative of all public and private HCWs. For example, none of the 31 included studies were from Europe. Also, India and Pakistan were highly overrepresented, with almost half of the 31 studies set in these two countries alone. Conversely, most of the studies either used random selection or included the complete target population, indicating that the participating HCWs should be representative of the target population.

In a separate study published in this series of the European Respiratory Journal, we assessed the prevalence of inappropriate TB treatment in populations of TB patients [6] and observed that, in $67 \%$ of the included studies, inappropriate regimens were prescribed. In the current article, all the included studies reported on HCWs' knowledge of TB regimens, and all showed a lack of knowledge among the different groups of HCWs. Even among the 10 studies on HCWs with experience in managing TB patients, knowledge was insufficient [25, 30-34, 38, 39, 48, 50]. Although the HCW study population in the current study does not link specifically to the settings in our assessment of prevalence of inappropriate treatment [6], the lack of knowledge among HCWs is a suggestive cause for the prevalence of inappropriate treatment regimens. In other words, if knowledge of appropriate TB regimens is insufficient, the actual prescription is most likely to also be insufficient. Indeed, a previous study assessing which TB treatment was actually prescribed by primary doctors showed that $75 \%$ made prescription errors with respect to one or more aspects of treatment. This included errors in treatment regimen $(45.2 \%)$, treatment duration $(64.5 \%)$ and drug dosages (30\%) [18]. In another study, in which a simulation patient was used, only two $(3.7 \%)$ prescriptions out of 53 met the required standards for TB patients as defined by the NTP [19]. These two studies measuring the actual practices are in line with the studies assessing HCW knowledge.

TB treatment consists of different treatment modalities: regimen; dose; frequency; and duration. Most of the 31 included studies provided information on treatment regimen $(91 \%, n=30)$, only a few studies provided information on dose $(19 \%, \mathrm{n}=6)$ or duration of the treatment regimen $(42 \%, n=13)$, and none of the studies provided information on the frequency of treatment (i.e. daily, thrice weekly, twice weekly, etc.). The adequacy of the knowledge of TB treatment could therefore only be assessed to a limited extent.

Unpublished studies cannot be found with a systematic review search strategy and were thus not included in our search strategies. It is possible that studies recording mainly adequate knowledge of treatment regimens are less frequently published than studies that measure and report on inadequate knowledge. If this is the case, overall knowledge of HCWs on TB treatment might be better compared to what we report herein.

10 out of the 31 studies included in our systematic review were identified by reviewing the references of included studies. These 10 studies did not contain the keywords that we used in our search strategy with regard to the title, abstract or keywords section. They did, however, contain the words "treatment" or "therapy" in the title or abstract. As the words "treatment" or "therapy" are not 
specific and would result in a very large number of records, we did not include them in our search strategy. With our search strategy and careful examination of the included studies' references, we believe that the majority of relevant published manuscripts on HCWs' knowledge of treatment were identified.

\section{Conclusion}

The available studies in this systematic review show that there is a lack of knowledge of the national or international guidelines and recommendations for TB treatment. Generalisation of the findings to other settings and countries should be done with caution.

\section{STATEMENT OF INTEREST}

None declared.

\section{ACKNOWLEDGEMENTS}

We would like to thank R. Spijker, clinical librarian at the Academic Medical Center Amsterdam (Amsterdam, The Netherlands), for assistance with development of the search strategy and for performing the search. We also would like to thank P. Carillo-Santisteve (European Centre for Disease Prevention and Control (ECDC), Stockholm, Sweden) for her assistance with retrieving the full-text papers.

\section{REFERENCES}

1 World Health Organization. Treatment of tuberculosis. Guidelines for national programmes. 1st Edn. Geneva, World Health Organization, 1993.

2 World Health Organization. Treatment of tuberculosis: guidelines for national programmes. 2nd Edn. WHO/TB/97.220. Geneva, World Health Organization, 1997.

3 World Health Organization. Treatment of tuberculosis: Guidelines for national programmes. 3rd Edn. WHO/CDS/TB/2003.313. Geneva, World Health Organization, 2003.

4 World Health Organization. Treatment of tuberculosis: guidelines. 4th Edn. WHO/HTM/TB/2009.420. Geneva, World Health Organization, 2009.

5 van der Werf MJ, Langendam MW, Huitric E, et al. Multidrug resistance after inappropriate tuberculosis treatment: a metaanalysis. Eur Respir J [Epub ahead of print DOI: 10.1183/ 09031936.00125711].

6 Langendam MW, van der Werf MJ, Huitric E, et al. Prevalence of inappropriate tuberculosis treatment regimens: a systematic review. Eur Respir J 2012; 39: 1012-1020.

7 Higgins JPT, Green S. Cochrane Handbook for Systematic Reviews of Interventions. Version 5.1.0. [Updated March 2011]. The Cochrane Collaboration, 2011.

8 Liberati A, Altman DG, Tetzlaff J, et al. The PRISMA statement for reporting systematic reviews and meta-analyses of studies that evaluate health care interventions: explanation and elaboration. Ann Intern Med 2009; 151: W65-W94.

9 Balasegaram S, Grant R, Ormerod P, et al. A survey of tuberculosis clinic provision in England and Wales. Public Health 2008; 122: 602-612.

10 Singh AA, Frieden TR, Khatri GR, et al. A survey of tuberculosis hospitals in India. Int J Tuberc Lung Dis 2004; 8: 1255-1259.

11 Sweni S, Meenakshisundaram R, Thirumalaikolundusubramanian P. Tuberculosis control: issues related to indigenous medical practitioners. Trop Med Int Health 2009; 14: Suppl. 2, 40.

12 Visperas JCG, Paulino J, Morfe JHD. Knowledge, attitudes, and practices for tuberculosis (TB) among medical clerks in a tertiarycare hospital. Respirology 2010; 15: Suppl. 2, 34.

13 Balabanova Y, Fedorin I, Kuznetsov S, et al. Antimicrobial prescribing patterns for respiratory diseases including tuberculosis in Russia: a possible role in drug resistance? J Antimicrob Chemother 2004; 54: 673-679.

14 Khan JA, Hussain SF. Anti-tuberculous drug prescribing: doctors' compliance at a private teaching hospital in Pakistan. Trop Doc 2003; 33: 94-96.

15 Uchiyama Y, Mao TE, Okada K, et al. An assessment survey of anti-tuberculosis drug management in Cambodia. Int J Tuberc Lung Dis 2006; 10: 153-159.

16 Lonnroth K, Lambregts K, Nhien DT, et al. Private pharmacies and tuberculosis control: a survey of case detection skills and reported anti-tuberculosis drug dispensing in private pharmacies in Ho Chi Minh City, Vietnam. Int J Tuberc Lung Dis 2000; 4: 1052-1059.

17 Rajeswari R, Balasubramanian R, Bose MS, et al. Private pharmacies in tuberculosis control - a neglected link. Int J Tuberc Lung Dis 2002; 6: 171-173.

18 Prasad R, Nautiyal RG, Mukherji PK, et al. Treatment of new pulmonary tuberculosis patients: what do allopathic doctors do in India? Int J Tuberc Lung Dis 2002; 6: 895-902.

19 Hussain A, Mirza Z, Qureshi FA, et al. Adherence of private practitioners with the National Tuberculosis Treatment Guidelines in Pakistan: a survey report. J Pakistan Medic Assoc 2005; 55: 17-19.

20 Bai LQ, Xiao SY, Xie HW, et al. [Knowledge and practice regarding tuberculosis among final-year medical students in Hunan, China.] Chung-Hua Chieh Ho Ho Hu Hsi Tsa Chih Chinese J Tuberc Respir Dis 2003; 26: 458-461.

21 Khan JA, Zahid S, Khan R, et al. Medical interns knowledge of TB in Pakistan. Trop Doc 2005; 35: 144-147.

22 Hashim DS, Al Kubaisy W, Al Dulayme A. Knowledge, attitudes and practices survey among health care workers and tuberculosis patients in Iraq. Eastern Medit Health J 2003; 9: 718-731.

23 Agarwal A, Arora A, Kumar S. A survey of prescribing pattern for osteoarticular tuberculosis: orthopaedic surgeons' and infectious disease experts' perspective. Indian J Tuberc 2009; 56: 201-205.

24 Roy SK, Roy SK, Bagchi S, et al. Study of KAP of the private medical practitioners about national disease control programmes. Indian J Public Health 2005; 49: 256-257.

25 Udwadia ZF, Pinto LM, Uplekar MW. Tuberculosis management by private practitioners in Mumbai, India: has anything changed in two decades? PLoS One 2010; 5: e12023.

26 Bhalla A, Chaisson RE. Why blame private practitioners? Chest 2001; 119: 1288.

27 Rajpal S, Mittal A, Dhingra VK, et al. Knowledge, attitude and practices regarding tuberculosis and dots among interns in Delhi, India. J Coll Physicians Surgeons Pakistan 2007; 17: 457-461.

28 Greaves F, Ouyang H, Pefole M, et al. Compliance with DOTS diagnosis and treatment recommendations by private practitioners in Kerala, India. Int J Tuberc Lung Dis 2007; 11: 110-112.

29 Vandan N, Ali M, Prasad R, et al. Physicians' knowledge regarding the recommended anti-tuberculosis prescribed medication regimen: a cross-sectional survey from Lucknow, India. Southeast Asian J Trop Med Public Health 2008; 39: 1072-1075.

30 Datta K, Bhatnagar T, Murhekar M. Private practitioners' knowledge, attitude and practices about tuberculosis, Hooghly district, India. Indian J Tuberc 2010; 57: 199-206.

31 Hurtig AK, Pande SB, Porter JDH, et al. Tuberculosis treatment and private practitioners, Kathmandu Valley. J Nep Med Assoc 2000; 39: 163-168.

32 Shah SK, Sadiq H, Khalil M, et al. Do private doctors follow national guidelines for managing pulmonary tuberculosis in Pakistan? Eastern Medit Health J 2003; 9: 776-788.

33 Rizvi N, Hussain M. Survey of knowledge about tuberculosis amongst family physicians. J Pak Med Assoc 2001; 51: 333-337.

34 Khan J, Malik A, Hussain H, et al. Tuberculosis diagnosis and treatment practices of private physicians in Karachi, Pakistan. Eastern Medit Health J 2003; 9: 769-775. 
35 Shehzadi R, Irfan $\mathrm{M}$, Zohra $\mathrm{T}$, et al. Knowledge regarding management of tuberculosis among general practitioners in northern areas of Pakistan. J Pakistan Medic Assoc 2005; 55: 174-176.

36 Ahmed M, Fatmi Z, Ali S, et al. Knowledge, attitude and practice of private practitioners regarding TB-DOTS in a rural district of Sindh, Pakistan. J Ayub Medic Coll Abbottabad: JAMC 2009; 21: 28-31.

37 Mahendradhata Y, Utarini A, Lazuardi U, et al. Private practitioners and tuberculosis case detection in Jogjakarta, Indonesia: actual role and potential. Trop Med Int Health 2007; 12: 1218-1224.

$38 \mathrm{Yu}$ CT, Zantua RRR, Tomas LJHS. Pulmonary tuberculosis: knowledge, attitudes and practices of selected physicians in a tertiary-care hospital. Philipp J Microbiol Infect Dis 2002; 31: 1-8.

39 Auer C, Lagahid JY, Tanner M, et al. Diagnosis and management of tuberculosis by private practitioners in Manila, Philippines. Health Policy 2006; 77: 172-181.

40 Portero JL, Rubio M. Private practitioners and tuberculosis control in the Philippines: strangers when they meet? Trop Med Int Health 2003; 8: 329-335.

41 Shirzadi MR, Majdzadeh R, Pourmalek F, et al. Adherence of the private sector to national tuberculosis guidelines in the Islamic Republic of Iran, 2001-2002. Eastern Medit Health J 2003; 9: 796-804.

42 Deveci SE, Turgut T, Acik Y, et al. [The knowledge, attitude and behavior related to the tuberculosis and approaches of tuberculosis therapy by the physicians providing first step service.] Tuberk Toraks 2003; 51: 40-47.

43 Cirit M, Orman A, Unlu M. Physicians' approach to the diagnosis and treatment of tuberculosis in Afyon, Turkey. Int J Tuberc Lung Dis 2003; 7: 243-247.

44 Shimeles E, Aseffa A, Yamuah L, et al. Knowledge and practice of private practitioners in TB control in Addis Ababa. Int J Tuberc Lung Dis 2006; 10: 1172-1177.

45 Ayaya SO, Sitienei J, Odero W, et al. Knowledge, attitudes, and practices of private medical practitioners on tuberculosis among HIV/AIDS patients in Eldoret, Kenya. East African Med J 2003; 80: 83-90.

46 Chakaya JM, Meme H, Kwamanga D, et al. Planning for PPMDOTS implementation in urban slums in Kenya: knowledge, attitude and practices of private health care providers in Kibera slum, Nairobi. Int J Tuberc Lung Dis 2005; 9: 403-408.
47 Suleiman BA, Houssein AI, Mehta F, et al. Do doctors in northwestern Somalia follow the national guidelines for tuberculosis management? Eastern Medit Health J 2003; 9: 789-795.

48 Nshuti L, Neuhauser D, Johnson JL, et al. Public and private providers' quality of care for tuberculosis patients in Kampala, Uganda. Int J Tuberc Lung Dis 2001; 5: 1006-1012.

49 Dato MI, Imaz MS. Tuberculosis control and the private sector in a low incidence setting in Argentina. Revista de Salud Publica 2009; 11: 370-382.

50 LoBue PA, Moser K, Catanzaro A. Management of tuberculosis in San Diego County: a survey of physicians' knowledge, attitudes and practices. Int J Tuberc Lung Dis 2001; 5: 933-938.

51 Menzies D, Benedetti A, Paydar A, et al. Effect of duration and intermittency of rifampin on tuberculosis treatment outcomes: a systematic review and meta-analysis. PLoS Med 2009; 6: e1000146.

52 Fox W, Ellard GA, Mitchison DA. Studies on the treatment of tuberculosis undertaken by the British Medical Research Council tuberculosis units, 1946-1986, with relevant subsequent publications. Int J Tuberc Lung Dis 1999; 3: Suppl. 2, S231-S279.

53 Elbireer S, Guwatudde D, Mudiope P, et al. Tuberculosis treatment default among HIV-TB co-infected patients in urban Uganda. Trop Med Int Health [Epub ahead of print DOI: 10.111/j.1365-3156.2011. 02800.X].

54 Vijay S, Kumar P, Chauhan LS, et al. Risk factors associated with default among new smear positive TB patients treated under DOTS in India. PLoS One 2010; 5: e10043.

55 Schaberg T, Rebhan K, Lode H. Risk factors for side-effects of isoniazid, rifampin and pyrazinamide in patients hospitalized for pulmonary tuberculosis. Eur Respir J 1996; 9: 2026-2030.

56 Gulbay BE, Gurkan OU, Yildiz OA, et al. Side effects due to primary antituberculosis drugs during the initial phase of therapy in 1149 hospitalized patients for tuberculosis. Respir Med 2006; 100: 1834-1842.

57 Breen RA, Miller RF, Gorsuch T, et al. Adverse events and treatment interruption in tuberculosis patients with and without HIV co-infection. Thorax 2006; 61: 791-794.

58 Torun T, Gungor G, Ozmen I, et al. Side effects associated with the treatment of multidrug-resistant tuberculosis. Int J Tuberc Lung Dis 2005; 9: 1373-1377.

59 Forget EJ, Menzies D. Adverse reactions to first-line antituberculosis drugs. Expert Opin Drug Saf 2006; 5: 231-249. 